\title{
O renascimento da diversidade no contexto da globalização
}

\author{
Regina Helena Giannotti
}

ORTIZ, Renato.

Universalismo e diversidade:

contradições da modernidade-mundo.

São Paulo: Boitempo, 175 p., 2015.

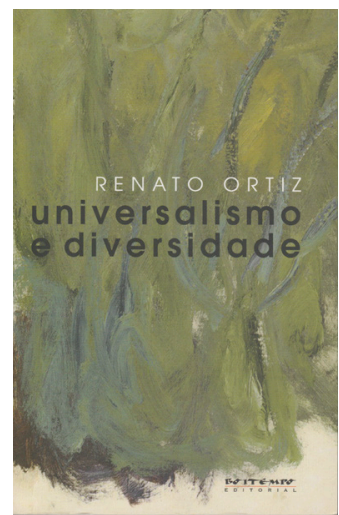

Resumo: Universalismo e diversidade: contradições da modernidade-mundo é um convite para refletir sobre temas contemporâneos, como diversidade, relativismo cultural e pluralismo, que podem ser analisados e compreendidos muito além das costumeiras dicotomias do pensamento eurocêntrico. Categorias de entendimento aceitas ao longo do século XX, como EstadoNação, universalismo e relativismo, ao serem atravessadas pelo processo de globalização, tiveram seus contextos de análise sensivelmente alterados, especialmente no que concerne às questões da temporalidade e espacialidade. Ultrapassando essa proposição, Ortiz alerta sobre os usos que a sociedade e o mercado têm feito do tema.

Palavras-chave: universalismo; globalização; diversidade; pluralismo.

Abstract: The revival of diversity in the context of globalization - Ortiz's book is an invitation to reflect on the themes of our era, like diversity, cultural relativism and pluralism, which must be analyzed and appreciated beyond the usual dichotomies of eurocentric thinking. Importante categories for understanding societies, as nation-state, universalism and relativism, when traversed by the globalization process, had their context analysis (temporality and spatiality) 
changed. In addition to this proposition, Ortiz make an alert of the uses that society and the market have made of this theme,

Keywords: universalism; globalization; diversity; pluralism.

Ao problematizar a temática da diversidade, presente já no título da obra lançada em 2015 pela editora Boitempo, Renato Ortiz reflete sobre as razões da ausência de um debate anterior em torno dos sentidos dessa forma específica de relação com as diferenças culturais. Por que não se compreendeu ou se estudou esse fenômeno antes? Partindo das ideias iluministas de civilização e progresso que ainda pautaram boa parte do pensamento ocidental ao longo do século XX, havia pouco espaço para que a importância da diferença pudesse se afirmar. Mas o advento da globalização, segundo Ortiz, abalou muitas das convicções existentes.

No capítulo intitulado A polissemia das palavras, o autor explora o duelo entre universalismo e relativismo, enquanto categorias de análise, para demonstrar em que medida o termo universal remete a diferentes tradições intelectuais e de sentidos. A metáfora da torre de Babel, definida como espaço de desentendimento e incompreensão, é utilizada para explicar o deslocamento da tensão do universal para o pluralismo da diversidade.

Explicita, ainda, como a lógica dicotômica típica do pensamento eurocêntrico percebe a história de forma linear e opera sob a lógica da excludência. Assim, Babel representa uma mancha na tradição, um regresso. O diverso é visto como uma maldição e o uno, como a noção do ideal. Partindo desses pressupostos, os intelectuais da época foram incapazes de compreender a complexidade do ambiente em que os processos culturais ocorriam, assim como as inúmeras relações que poderiam ser articuladas entre o homem e a natureza. Entre os principais pensadores do iluminismo, como Rousseau, Montesquieu e Voltaire, havia o entendimento do universal como uma qualidade da natureza humana cujo ponto de partida de todas as definições era o próprio homem. É desnecessário dizer o quão precárias foram as classificações feitas a partir dos padrões estabelecidos pelo mundo ocidental.

Apesar de sabermos que há uma unificação do mundo do ponto de vista político e econômico a partir da globalização, Ortiz adverte que essa metáfora do mundo plano, nivelado pelas expectativas e necessidades de consumo, é uma ilusão daqueles que pensam a realidade social apenas do ponto de vista tecnológico e econômico. A exemplo do que ocorreu com as problemáticas da sociologia tradicional do século XIX, chamadas por Octavio lanni de emblemas, ou um conjunto de reflexões que giram em torno de um eixo comum, na modernidade-mundo o emblema que emerge é o da diversidade. A crescente transnacionalização das economias, quando atravessadas pela situação-globalização, tanto reorientou quanto reduziu a capacidade decisória dos governos nacionais. Não é de causar estranheza que a temática da diversidade tenha adquirido relevância nos últimos 
tempos. Afinal, à medida que o mundo se unifica, a diferença apresenta-se como uma fonte de riqueza, de patrimônio a ser preservado, ao mesmo tempo em que se torna uma fonte potencial de conflitos.

Com o objetivo de escapar das armadilhas contidas na conceituação, Ortiz ocupa-se também da relevância que o termo universal adquire quando é transposto para o campo das tradições intelectuais. Como a razão e a liberdade eram os principais temas do iluminismo, enquanto os filósofos postulavam a existência de um homem guiado pela razão, os linguistas, em contrapartida, atribuíam sentido à existência do homem e sua distinção entre sociedade e natureza, assim como entre língua e linguagem. A linguagem, como afirma Saussure, é "uma faculdade universal, uma capacidade inerente à condição humana, enquanto a língua seria o conjunto de formas concordantes que este fenômeno assume numa coletividade de indivíduos e numa época determinada" (ORTIZ, 2015, p.16). Dito de outra forma, "o mundo lhes ocorria de certa forma, por meio da diversidade de línguas e não da linguagem que é uma faculdade universal dos seres vivendo em sociedade; o universal termina onde começam a cultura e a língua", afirma (ORTIZ, 2015, p.19).

Portanto, salienta o autor, é somente no momento em que a linguagem se afirma em sua plenitude, incluindo a capacidade de análise, de interpretação, de estruturação da realidade e da função argumentativa ou de elaboração do discurso, que ocorre a inversão cultural; ou seja, cessa a evolução biológica do homo sapiens e inicia-se a evolução cultural. A partir desse ponto, a sociedade passa a se organizar de outra forma, incorporando elementos da cultura. Assim, à medida que as categorias de análise são sobrepostas à categoria do universalismo, a noção de diversidade, relacionada à natureza, perde força. A tradição intelectual da sociologia passa a se ocupar de analisar o homem a partir de realidades empíricas, em contextos, e não a partir de princípios normativos ou filosóficos. Ganham espaço os dispositivos de universalização, como a escrita e a religião. A escrita promove a descontextualização das normas e a religião age como um centro irradiador de sentidos.

Já em Tradição e modernidade, terceiro capítulo, a questão central explorada pelo autor é a de saber se os que haviam sucedido os pensadores dos séculos XVII e XVIII eram uma fonte exclusiva do saber ideal. Enquanto o período das Luzes assiste ao progresso das ciências, o século XIX assiste ao desenvolvimento da técnica aplicada ao progresso material. A ideia de progresso precisou esperar as conquistas do industrialismo e as transformações políticas para romper com a ordem aristocrática e monárquica. A reorganização do trabalho e da vida social serviu de base para muitos estudos de Marx, por exemplo. Os mecanismos da vida moderna são modificados quando a técnica alcança o cotidiano das pessoas. Como destaca o autor, "o conjunto de utensílios passa a habitar as casas: pia, banheiro, privada, navalha de barbear, escova de dente; nos escritórios: mata-borrão, borracha, grampeador, clipe, apontador de lápis" (ORTIZ, 2015, p. 67).

Ao adentrar a vida privada, a ideia de progresso, antes restrita ao plano filosófico, passa a abranger diferentes esferas da sociedade. Constrói-se uma narrativa que abarca 
os valores, a economia, as instituições políticas, a vida material, tornando-se um ideal de civilização. O autor pondera que, se a história possuía um sentido único, o futuro poderia ser projetado a partir do presente. Nesse sentido, o plano da razão eliminaria as etapas anteriores da vida social e projetaria esperanças de um mundo melhor. Ao utilizar uma concepção linear do tempo para explicar o paradoxo da tradição/modernidade impõe-se, necessariamente, um constante processo de evolução. Diferente da realidade social anterior, a revolução industrial exigia a regência do tempo; pontualidade e exatidão tornamse exigências sociais e de valor, ao mesmo tempo em que ditam o ritmo do progresso.

Diversamente de outras áreas do conhecimento em que a ideia evolucionista parece dar conta de explicar os fenômenos sociais, a proposta culturalista sugere o contrário. É o que argumenta Ortiz no quarto capítulo, intitulado Sobre o relativismo cultural. A partir da contraposição dos métodos de pesquisa utilizados pela Antropologia (comparativismo) e dos métodos dos culturalistas (difusionismo, que parte da existência de núcleos de irradiação dos traços culturais), o objetivo dos culturalistas era compreender a alteridade. A diferença entre uma e outra reside na forma como as variações entre as sociedades foram traduzidas. O relativismo cultural parte do pressuposto de que quando uma sociedade é posta em contato com outra faz-se necessário a prática da tolerância entre os códigos de ambas para assegurar a sobrevivência mútua. Foi com base nesse entendimento que surgiu, por exemplo, a carta dos Direitos Humanos da ONU, em 1947, esclarece Ortiz. O maior mérito do relativismo cultural, segundo o autor, foi o de inocular a sensibilidade pelo diverso.

Mas é no capítulo intitulado Diversidade e mercado que se evidenciam os diferentes usos atribuídos à cultura e o uso político do tema da diversidade. Ortiz critica duramente os autores da literatura de administração, especialmente ao destacar as interpretações em torno do emblema da modernidade-mundo: a diversidade. Como a empresa moderna está ancorada nos pressupostos da racionalidade e da eficiência, há necessidade de se erigir "um novo saber com o objetivo de ordenar o campo dos negócios tornando-o mais produtivo e rentável" (ORTIZ, 2015, p. 114). A metáfora da "mão visível do mercado", uma contraposição de Alfred Chandler à "mão invisível do mercado" de Adam Smith, é utilizada pelo autor para explicar as alterações nas formas de gestão imputadas pela globalização, pela adoção do olhar de um mundo plano e pela crença na existência de uma linguagem universal do consumo, capaz de nos integrar no seio de um território compartilhado.

Por fim, na seção intitulada Anexos: imagens do Brasil Ortiz explicita como a questão da diversidade é observada e tratada no Brasil e na América Latina. As questões da brasilidade, da linearidade do tempo e do espaço têm construído novas imagens sobre o nacional. Das pretensões contidas na marca Brasil às combinatórias que podem ser criadas no contexto nacional e internacional, o autor afirma como os símbolos nacionais foram cunhados e estão sendo substituídos para explicar a realidade social do país. A situação da globalização nos impele a rever todas as certezas que foram consolidadas ao longo do tempo. 
Regina Helena Giannotti é publicitária e doutoranda do Programa de Estudos Pós-Graduados em Comunicação e Semiótica da PUC-SP.

rgiannotti@uol.com.br

regina.giannotti@icloud.com

\section{Referências}

IANNI, Octávio. Globalização: novo paradigma das ciências sociais. Estud. av. [online]. 1994, vol. 8, n. 21, pp. 147-163. ISSN 1806-9592. Disponível em: <http://dx.doi.org/10.1590/S010340141994000200009>. Acesso em: 15 mai. 2016. 